\title{
Perineal infiltration with levobupivacaine or placebo for episiotomies or second-degree tears: A double-blind randomized study
} \author{
Ayoubi $^{1}$ \\ ${ }^{1}$ Department of Obstetrics and Gynecology, Foch University Hospital, Suresnes, France \\ ${ }^{2}$ Department of Obstetrics and Gynecology, Les Bluets Hospital, Paris, France \\ ${ }^{3}$ Department of Clinical Research HU PIFO, AP-HP, Ambroise Paré University Hospital, Boulogne, France \\ ${ }^{4}$ Department of Anesthesia and Reanimation, Foch University Hospital, Suresnes, France
}

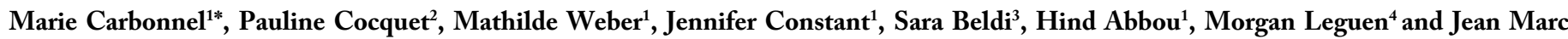

\begin{abstract}
Introduction: The purpose of this study was to investigate whether a single perineal infiltration of levobupivacaine administered immediately before repairing a perineal second-degree tear or episiotomy decreased pain in women after delivery.

Materials and methods: This randomized controlled double-blind study included women at low risk with spontaneous (unassisted) or vacuum-assisted vaginal delivery at Foch University Hospital, Suresnes, France. The treatment group $(\mathrm{L})(\mathrm{n}=54)$ received a perineal infiltration of $10 \mathrm{~mL}$ levobupivacaine $(5 \mathrm{mg} / \mathrm{mL})$ $\left(\right.$ Chirocaine $\left.^{6}\right)$ and the placebo control group $(\mathrm{P})(\mathrm{n}=50)$ a perineal infiltration of $10 \mathrm{~mL}$ saline solution $(0.9 \%)$ immediately before perineal repair of a second-degree tear or an episiotomy after delivery. The primary outcome variable was the mean resting numeric rating scale (NRS) for pain intensity at 8 hours. The secondary outcome variables were mean resting NRS for pain intensity at 2, 4, 12, 24, 36, and 48 hours, and in motion, the safety of levobupivacaine, analgesic consumption, and patient satisfaction scores. At 1 month, the women received a questionnaire to assess pelvic pain and its repercussions, analgesic use, and complications.
\end{abstract}

Results: The study included 104 women. Demographic data were comparable for the experimental and control groups. The NRS pain scores were low and did not differ between the groups; nor did the groups differ for mean pain intensity, patient satisfaction, or analgesic use either during the 48 hours after delivery or at 1 month.

Conclusions: Levobupivacaine infiltration into an episiotomy wound or perineal tear did not appear to reduce pain significantly among women at low risk.

\section{Abbreviations: NRS: Numeric Rating Scale}

Key Message: Levobupivacaine infiltration into an episiotomy wound or perineal tear did not appear to reduce pain significantly among women at low risk (that is, a spontaneous or unassisted vaginal delivery or vacuum extraction) receiving oral analgesics and antiinflammatory agents.

\section{Introduction}

Postpartum perineal pain is not rare. An Australian study published in 2012 showed that $37 \%$ of 215 women with a vaginal delivery reported moderate to severe perineal pain in the 72 hours afterwards [1]. While this pain peaks in the immediate postpartum period, discomfort or even intense pain can persist for several weeks after delivery [2]. The principal causes of perineal pain are tears or lacerations and episiotomies [3]. The intensity of pain is correlated with the extent of the injury, as shown in a Canadian study where $60 \%$ of women with first- and second-degree lacerations complained of pain on day 7 after delivery, $71 \%$ of those with episiotomies, and $91 \%$ with third- or fourth-degree lacerations; pain was still present at 6 weeks for respectively 4\%,13\% and 20\% [4]. Episiotomy is the most common surgical procedure for parturients [5]. The recommendation of a restrictive episiotomy policy by recent clinical practice guidelines has led to a decrease in the use of this procedure [6]. Nonetheless, the episiotomy rate in France in 2010 was still $44.4 \%$ for nulliparas and $14.3 \%$ for multiparas [7]. Studies of obstetric analgesia have focused on pain during labor or after a cesarean delivery, with less attention paid to analgesia after vaginal delivery [8]. Nonetheless beyond the physical discomfort it causes, postpartum pain can have multiple consequences, disrupting breastfeeding and both caring for and bonding with the baby [9]. Over the longer term, it can also affect the mother's sexual life [10]. Postpartum pain management is based principally on oral drugs: paracetamol and non-steroidal antiinflammatory drugs (NSAIDs) [11]. Very small quantities of NSAIDs pass into breast milk, but their use is often limited in time (e.g., a single administration) [12]. Any ineffectiveness is a problem, since the next choice-morphine-does transfer into breast milk and has adverse effects.

Correspondence to: Marie Carbonnel, Department of Obstetrics and Gynecology, Foch University Hospital, Suresnes, France, E-mail: carbonnelmarie@gmail.com

Key words: delivery, episiotomy, levobupivacaine, infiltration, pain, tear, perineal Received: July 10, 2017; Accepted: August 18, 2017; Published: August 21, 2017 
The analgesic efficacy of infiltration before suturing has been shown in many types of surgery $[13,14]$. Infiltration is defined as the injection of an analgesic agent (most often a long-acting anesthetic) in a subcutaneous space near the surgical site. Unlike regional blocks, it does not require identification of nerve locations, and is thus an easy procedure that can be performed by midwives, obstetricians, and anesthetists. It acts by blocking distal nerve endings. It also helps to break the "pain inflammation" loop and thus provides better control of secondary hyperalgesia [15]. This explains its effectiveness on parietal pain, for several days beyond its theoretical duration of action [14,16,17]. This technique therefore seems interesting for the management of perineal pain after episiotomy or tears. Thus far, very few studies have looked at this subject, and their results are contradictory [18-21]. The purpose of this study was to investigate whether a perineal single infiltration of levobupivacaine immediately before repairing a perineal tear or episiotomy could decrease pain in women 8 hours after delivery. We performed a randomized, double-blind, controlled study.

\section{Material and methods}

Women were included from January 2011 to September 2014 in the obstetrics department of Foch University Hospital, in Suresnes, France. It was approved by the appropriate ethics committee and registered (ClinicalTrials.gov, NCT02905695). Women received written information about the trial during prenatal care and provided written informed consent at the last visit for prenatal care before delivery or at the beginning of labor. Inclusion criteria were vaginal delivery, spontaneous or vacuum-assisted vaginal delivery, with a mediolateral episiotomy or second-degree perineal tear requiring three planes suturing, singleton fetus in a vertex position, maternal age of 18-45 years, effective epidural labor analgesia, and coverage by a national health insurance fund. For practical reasons, the women had to understand and write the French language. Exclusion criteria were delivery with ineffective or no epidural analgesia, contraindication to local anesthetics or levobupivacaine, multiple pregnancy, breech delivery, or operative vaginal delivery assisted by forceps or spatula, an anterior tear requiring sutures, first-, third or fourth degree perineal tear, or continuous sutures with one thread and one knot for all the plans. The contraindications to levobupivacaine are include an allergy to amino amides, porphyria, intracardiac conduction disorders, uncontrolled epilepsy, history of malignant hyperthermia, or severe arterial hypotension. An epidural was defined as ineffective when the numerical rating scale (NRS) $>3$ at the moment of the episiotomy incision or if additional local anesthetic infiltration was necessary. Final inclusion and randomization took place immediately before the obstetrician or midwife started to suture the episiotomy or tear; a computer-generated randomization list allocated each participant to levobupivacaine $(5 \mathrm{mg} / \mathrm{mL})$ or placebo (saline prepared in strictly similar $10-\mathrm{mL}$ syringes). Each randomization number had a corresponding sealed, opaque envelope that contained information about the study treatment. The envelope was opened in another room by the nurse, who prepared the syringes according to the randomization sequence to insure blinding of the patients, midwives, obstetricians, and anesthesiologists. A senior midwife or an obstetrician injected $10 \mathrm{~mL}$ of the randomly allocated compound along both sides after the episiotomy incision or tear and only then sutured the incision or tea with a continuous suture technique for vaginal repair (Vicryl 2/0; Ethicon, Somerville, NJ, USA) and interrupted stitches for deeper tissues (Vicryl 0) and the perineal skin (Vicryl Rapide 2/0). The epidural analgesia controlled by the parturient consisted of a mixture of levobupivacaine $0.125 \mathrm{mg} / \mathrm{mL}$, sufentanil $0.25 \mu \mathrm{g} / \mathrm{mL}$, and clonidine $0.375 \mu \mathrm{g} / \mathrm{dL}$, with a loading dose of $8-10 \mathrm{~mL}$, a continuous infusion of $4 \mathrm{~mL} /$ hour, and additional bolus of $6 \mathrm{~mL}$ every $30 \mathrm{~min}$. Quality of the analgesia was assessed during the first hour to obtain symmetrical analgesia and maintain motor response. Mothers did not walk during the study period. The epidural catheter was removed 2 hours after delivery, before the women returned to her room. Incidents related to the injection of local anesthesia were recorded. The women received a questionnaire, asking them to rank their perineal pain on the NRS from "no pain" (corresponding to 0 ) to "the worst possible pain" (corresponding to 10) at 2, 4, 8, 12, 24, 36, and 48 hours after delivery at rest and on motion. They were also instructed to take analgesics only in the case of pain (NRS>3) and to record what they take (quantity and type: paracetamol, ketoprofen, tramadol, nefopam) at D0, D1, and D2. Maternal satisfaction for perineal pain relief during the first 48 hours was also investigated on a different NRS $(0=$ very poor, $1=$ poor, $2=$ good, $3=$ very good). A month after delivery, a new questionnaire was sent to the women, to assess pain according to the NRS for pain (pain at the moment, the most intense pain in the last 8 days, and the usual pain over the last 8 days), the analgesics taken during those 8 days, and the effects of this pain on mood, walking, usual daily tasks, and maternal tasks (child care). Finally it asked about complications related to the perineum.

The primary data collected included: the woman's weight and weight gain during pregnancy, number of pregnancies, parity, term at delivery, duration of labor, duration at full dilatation, mode of delivery (spontaneous or vacuum extraction), presence of a tear $<3 \mathrm{~cm}$ or $\geq$ $3 \mathrm{~cm}$, of an episiotomy $<3 \mathrm{~cm}$ or $\geq 3 \mathrm{~cm}$, presence of hemorrhoids, birth weight, head circumference, and quantity of levobupivacaine in the epidural analgesia.

The study sample size estimation was based on results of a previous publication [20]. To obtain a type I error of 5\% and power of $80 \%$ required that the study include at least 45 women in each group to detect a significant improvement in the NRS. To reinforce the study power, 55 patients were required in each group. The R 2.15.0 software was used to conduct the stratified analysis on the type of lesion (episiotomy or tear of the first degree) between patients with levobupivacaine and placebo treatment. Baseline characteristics of the patients were summarized and compared between the two groups. Quantitative data were reported as median and interquartile range, qualitative or binary data were reported as number and percentage.

This study is reported in accordance with the CONSORT Statement (Figure 1 = Consort flow diagram).

The primary study endpoint was the NRS score 8 hours after delivery at rest. The resting pain intensity rating scale at 2, 4, 12, 24, 36, 48 hours and while in motion, levobupivacaine safety, analgesic consumption, and women's satisfaction scores were considered secondary endpoints.

The primary outcome was analyzed for both the intention-to-treat (ITT) and per protocol (PP) populations. The secondary outcomes were analyzed only in the ITT population. The ITT population comprised all women who were included and randomized. The PP population excluded those with no episiotomy or perineal tear, who did not have an effective epidural, or a singleton pregnancy in cephalic presentation, who did not give birth by spontaneous or vacuumassisted delivery, who did not receive either treatment, or who did not receive the allocated treatment. The missing measurements were imputed by the "last observation carried forward (LOCF)" method. The missing data for the primary outcome were also imputed by multiple imputations for a sensitivity analysis. The Van Elteren test was used to assess the difference between the groups in pain intensity at 8 hours 


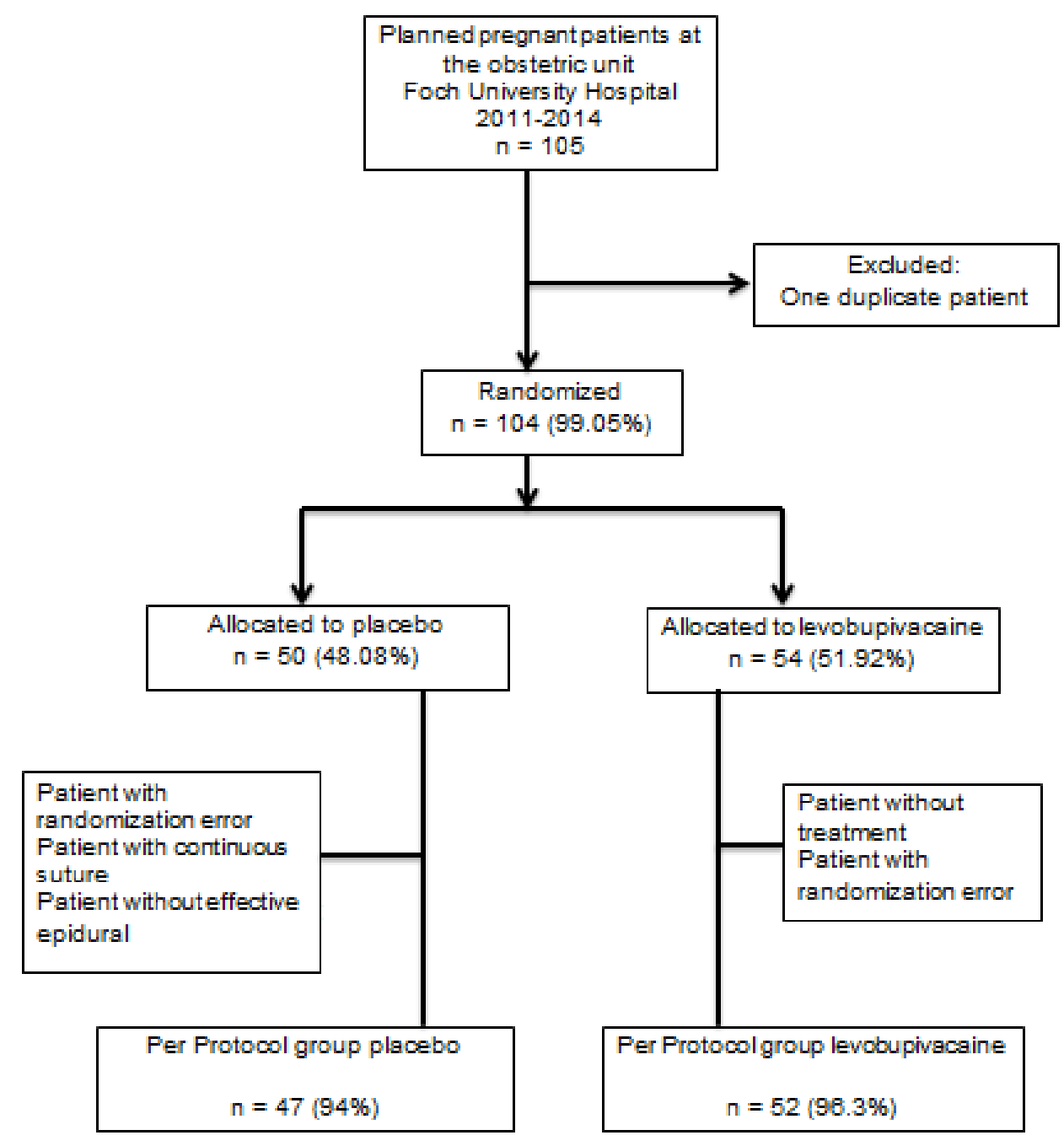

Figure 1. Consort flow diagram.

after suture (primary outcome). The secondary criteria were assessed with the Cochran-Mantel-Haenszel test for qualitative data and with the Van Elteren test for quantitative data. Subgroup analyses to test for interactions compared the women with an episiotomy to those with a second-degree tear and those with spontaneous delivery to those with vacuum-assisted delivery with vacuum extractor according to treatment group. A $p$ value $\leq 0.05$ was considered significant.

\section{Results}

The study randomized 105 women. Six were excluded: 1 for duplicate randomization, 2 for erroneous randomization, 2 who did not meet the inclusion criteria (ineffective epidural analgesia and a continuous suture) and one who did not receive any treatment (Figure 1). Table 1 summarizes the demographic data. The levobupivacaine group (L) and the placebo or control group (C) did not differ for baseline characteristics, labor, or delivery. All episiotomies and tears healed uneventfully. NRS at 8 hours did not differ between the two groups (mean for group L: $1[0.0 ; 2.0] /$ mean for group P: $1.6[0.0 ; 3.0]$, $P=0.8$ ). Pain intensity was low during the first 48 -h study period, with no difference between groups. The mean resting NRS for pain intensity at 2, 4, 12, 24, 36, 48 hours and in motion were equivalent (Figure 2 and 3). Antalgic consumption, was similar (Table 2). Maternal satisfaction for perineal pain relief during the first 48 hours was similar in the two group (median NRS $2[2.0 ; 3.0]=$ good in the two groups, $P=0.93$ ). Levobupivacaine appeared to be safe, and no adverse effects were reported. We found two immediate complications for one patient in the placebo group: a third-stage hemorrhage and a breach of the dura mater, neither attributable to the protocol. We found one scar dehiscence in the control group and 2 in the levobupivacaine group. None required surgical revision. Subgroup analyses for the principal criterion sought to determine the existence of any interactions between the treatment effect and one or more variables. No difference was observed in the following subgroups: episiotomy (NRS L/C: 1.54/1.98 $P=0.328)$, tears $(1.89 / 0.86 P=0.401)$, spontaneous delivery (NRS L/C: $1.89 / 1.6 P=0.99)$ and vacuum extraction (NRS L/C: $1 / 1.62 P=0.284$ ).

Overall, 8 women in the levobupivacaine group and 9 in the control group did not respond to the questionnaire at 1 month. We observed no difference in perineal pain or its repercussions or analgesic intake (Tables 2 and 3). No complication attributable to the injection was reported at 1 month.

\section{Discussion}

Three potent and therefore long-acting local anesthetic agents are available: bupivacaine (Marcaine ${ }^{\circ}$, ropivacaine (Naropein ${ }^{\circ}$, 
Table 1. Characteristics of the study population.

\begin{tabular}{|c|c|c|c|c|}
\hline & & $\begin{array}{l}\text { Group P } \\
\mathbf{N}=\mathbf{5 0}\end{array}$ & $\begin{array}{l}\text { Group L } \\
\mathbf{N}=\mathbf{5 4}\end{array}$ & $P$-value \\
\hline Gravida & $\begin{array}{l}\mathrm{n} \\
1 \\
2 \\
3 \\
4\end{array}$ & $\begin{array}{l}49 \\
25(51.02 \%) \\
15(30.61 \%) \\
3(6.12 \%) \\
6(12.24 \%)\end{array}$ & $\begin{array}{l}54 \\
29(53.7 \%) \\
17(31.48 \%) \\
6(11.11 \%) \\
2(3.7 \%)\end{array}$ & $0.386^{\mathrm{c}}$ \\
\hline Parity & $\begin{array}{l}\mathrm{n} \\
1 \\
2 \\
3 \\
4\end{array}$ & $\begin{array}{l}49 \\
34(69.39 \%) \\
11(22.45 \%) \\
2(4.08 \%) \\
2(4.08 \%)\end{array}$ & $\begin{array}{l}54 \\
39(72.22 \%) \\
15(27.78 \%) \\
0(0 \%) \\
0(0 \%)\end{array}$ & $0.216^{\mathrm{c}}$ \\
\hline Previous vaginal delivery & n $(\%)$ & $11(22.45 \%)$ & $13(24.53 \%)$ & $0.985^{\mathrm{c}}$ \\
\hline Genital mutilation & n $(\%)$ & $0(0 \%)$ & $0(0 \%)$ & $1^{\mathrm{c}}$ \\
\hline Weight before pregnancy (kg) & Median [IQR] & $60[55-66]$ & $58[54-65]$ & $0.388^{v}$ \\
\hline Weight gain during pregnancy (kg) & Median [IQR] & 13 [11-17] & $13[10-18]$ & $0.815^{\mathrm{v}}$ \\
\hline Gestationnal age at birth (week) & Median [IQR] & 38 [37-39] & $38[37-38.8]$ & $0.618^{v}$ \\
\hline Working time (min) & Median [IQR] & $390[300-490]$ & $360[300-540]$ & $0.578^{v}$ \\
\hline Full expansion time (min) & Median [IQR] & $105[60-130]$ & $76.5[51-131.2]$ & $0.414^{v}$ \\
\hline $\begin{array}{l}\text { Amount of epidural } \\
\text { levobupivacaine }(\mathrm{mg})\end{array}$ & Median [IQR] & 75 [54.7-106.8] & 75 [55.6-96.9] & $0.604^{\mathrm{v}}$ \\
\hline Vaccum extraction & n (\%) & $10(20.41 \%)$ & $12(22.22 \%)$ & $0.767^{\mathrm{c}}$ \\
\hline Tear length $(\mathrm{cm})$ & $\begin{array}{l}\mathrm{n} \\
<3 \mathrm{~cm} \\
\geq 3 \mathrm{~cm}\end{array}$ & $\begin{array}{l}19 \\
4(21.05 \%) \\
15(78.95 \%)\end{array}$ & $\begin{array}{l}24 \\
11(45.83 \%) \\
13(54.17 \%)\end{array}$ & $0.075^{\mathrm{c}}$ \\
\hline Episiotomy length $(\mathrm{cm})$ & $\begin{array}{l}\mathrm{n} \\
<3 \mathrm{~cm} \\
\geq 3 \mathrm{~cm}\end{array}$ & $\begin{array}{l}32 \\
14(43.75 \%) \\
18(56.25 \%)\end{array}$ & $\begin{array}{l}32 \\
20(62.5 \%) \\
12(37.5 \%)\end{array}$ & $0.21^{\mathrm{c}}$ \\
\hline hemorrhoids & n (\%) & $12(24.49 \%)$ & $15(28.3 \%)$ & $0.634^{c}$ \\
\hline Birth weight $(\mathrm{kg})$ & Median [IQR] & $3.4[3-3.7]$ & $3.3[3.1-3.5]$ & $0.201^{\mathrm{v}}$ \\
\hline Cephalic perimeter $(\mathrm{cm})$ & Median [IQR] & 34 [33.5-35] & $34.8[34-35]$ & $0.657^{\mathrm{v}}$ \\
\hline
\end{tabular}

$\mathrm{n}=$ number of data items entered, $(\%)=$ percentage of data entered, IQR $=$ Interquartile range

c Cochran-Mantel-Haenszel test, v Van Elteren test

$\mathrm{kg}=$ kilogram, $\mathrm{min}=$ minutes, $\mathrm{mg}=$ milligram, $\mathrm{cm}=$ centimeter

Table 2. Analgesic use.

\begin{tabular}{|c|c|c|c|c|}
\hline & & $\begin{array}{c}\text { Group P } \\
\text { n (\%) }\end{array}$ & $\begin{array}{c}\text { Group L } \\
\text { n (\%) }\end{array}$ & p-value ${ }^{c}$ \\
\hline $\begin{array}{c}\text { n d0-2 (\%) } \\
\text { n m1(\%) }\end{array}$ & & $\begin{array}{l}43(100 \%) \\
39(100 \%)\end{array}$ & $\begin{array}{l}46(100 \%) \\
45(100 \%)\end{array}$ & \\
\hline Analgesic use & $\begin{array}{l}\mathrm{d} 0 \\
\mathrm{~d} 1 \\
\mathrm{~d} 2 \\
\mathrm{~m} 1\end{array}$ & $\begin{array}{c}34(79 \%) \\
39(90.7 \%) \\
34(79 \%) \\
7(17.9 \%)\end{array}$ & $\begin{array}{l}36(78.2 \%) \\
43(93.5 \%) \\
35(76.1 \%) \\
8(17.78 \%)\end{array}$ & $\begin{array}{l}0.83 \\
0.54 \\
0.77 \\
0,99\end{array}$ \\
\hline Paracetamol & $\begin{array}{l}\mathrm{d} 0 \\
\mathrm{~d} 1 \\
\mathrm{~d} 2 \\
\mathrm{~m} 1\end{array}$ & $\begin{array}{c}33(76,7 \%) \\
38(88,4 \%) \\
34(79 \%) \\
7(17.9 \%)\end{array}$ & $\begin{array}{c}36(78.2 \%) \\
43(93.5 \%) \\
34(74 \%) \\
8(17.78 \%)\end{array}$ & 1 \\
\hline Ketoprofen & $\begin{array}{l}\mathrm{d} 0 \\
\mathrm{~d} 1 \\
\mathrm{~d} 2 \\
\mathrm{~m} 1\end{array}$ & $\begin{array}{c}23(53.5 \%) \\
28(65.1 \%) \\
22(51.1 \%) \\
1(2.5 \%)\end{array}$ & $\begin{array}{c}22(47.8) \\
27(58.7) \\
19(41.3) \\
0\end{array}$ & 1 \\
\hline Nefopam & $\begin{array}{l}\mathrm{d} 0 \\
\mathrm{~d} 1 \\
\mathrm{~d} 2 \\
\mathrm{~m} 1\end{array}$ & $\begin{array}{c}2(4.6 \%) \\
6(13.9 \%) \\
4(9.3 \%) \\
1(2.5 \%)\end{array}$ & $\begin{array}{c}7(15.2 \%) \\
8(17.4 \%) \\
4(8.6 \%) \\
0\end{array}$ & 1 \\
\hline Tramadol & $\begin{array}{l}\mathrm{d} 0 \\
\mathrm{~d} 1 \\
\mathrm{~d} 2 \\
\mathrm{~m} 1\end{array}$ & $\begin{array}{l}0 \\
0 \\
0 \\
0\end{array}$ & $\begin{array}{c}0 \\
1(2.2 \%) \\
0 \\
0\end{array}$ & 1 \\
\hline
\end{tabular}

$\mathrm{n}=$ number of data items entered, $\mathrm{c}$ Cochran-Mantel-Haenszel, $\mathrm{d}=$ day, $\mathrm{m}=\mathrm{month}$

and levobupivacaine (Chirocaine). Bupivacaine is more toxic and has a shorter period of action than the others and accordingly has no marketing authorization for local infiltrations. The toxicity of ropivacaine is lower than for both the others. Levobupivacaine appears to have an intermediate level of toxicity, but also, according to some authors, greater efficacy than ropivacaine [22,23]. Moreover, we are currently using levobupivacaine in our epidural analgesia. Accordingly we chose this anesthetic agent for the local infiltrations, although it has never been studied in episiotomies. When good practice guidelines are followed and the toxic dose is not exceeded, complications are rare: an aspiration test was routinely performed before injection to avoid intravascular injection, which is the leading cause of adverse effects; the injection was slow and fractionated with monitoring of vital signs and clinical state in the minutes after injection. No serious accident attributable to parietal infiltration has been reported in our series or in the literature. Nor did we find more scar dehiscence at 1 month attributable to levobupivacaine, as others have reported [24]. The maximum recommended dose in a single injection is $150 \mathrm{mg}$, which corresponds to $30 \mathrm{~mL}$ as a $5 \mathrm{mg} / \mathrm{mL}$ solution. Moreover the maximum recommended dose over a 24-hour period is $400 \mathrm{mg}$ [25]. We therefore chose to inject $10 \mathrm{~mL}$ as a $5 \mathrm{mg} / \mathrm{mL}$ solution to remain below the toxic dose. Pain was assessed for the first 48 hours at rest and while moving. Although the potential effect of long-acting local anesthetics peaks in the first 12 hours, studies show that an effect continues in the hours and even days that follow $[14,16,17]$. We note in our series that the mean pain scores were low with nonetheless considerable analgesic intake. Although women were asked not to take treatment routinely but only in cases of pain with NRS $>3$, we cannot be certain that these oral analgesics were not used more routinely, consistent with general practices in the department (Figure 3).

We sought to study a uniform population with the least possible bias. Accordingly, we excluded operative vaginal deliveries with forceps or spatulas as well as third- and fourth-degree perineal lacerations, 


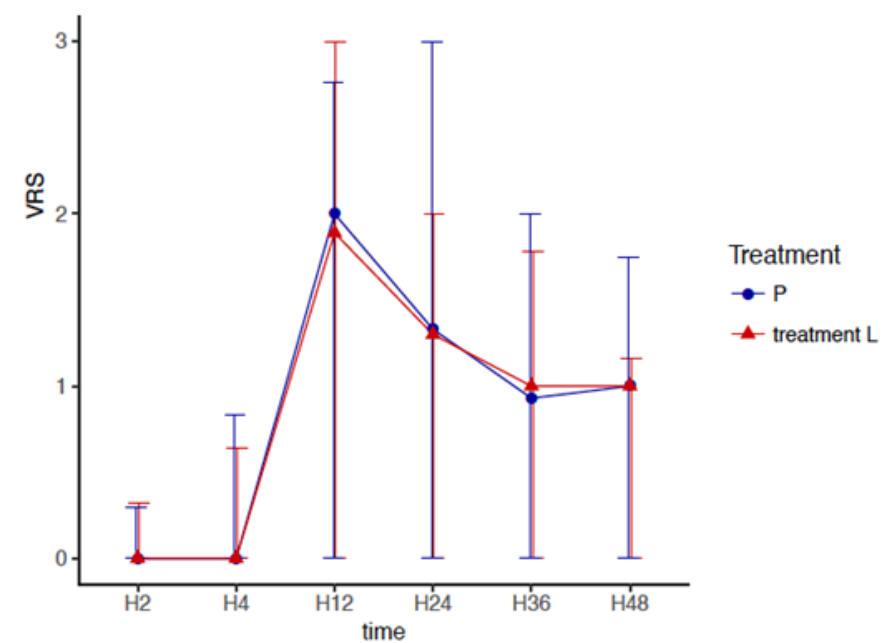

Figure 2. Median [range] NRS for resting pain assessment during the first $48 \mathrm{~h}$ after suturing.

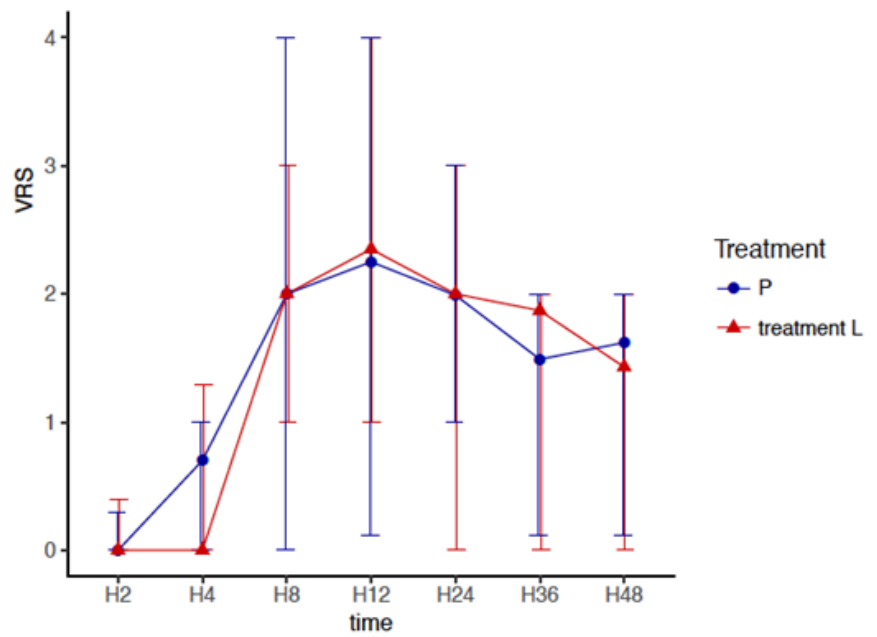

Figure 3. Median [range] NRS for mobilization pain assessment during the first postoperative 48 hours.

Table 3. NRS 1-month pain.

\begin{tabular}{|c|c|c|c|}
\hline & $\begin{array}{l}\text { Group P } \\
(\mathbf{N}=\mathbf{5 0})\end{array}$ & $\begin{array}{l}\text { Group L } \\
(N=54)\end{array}$ & Pvalue $^{v}$ \\
\hline \multicolumn{4}{|c|}{ Median [IQR] } \\
\hline Pain right now & $2[2-3]$ & $2[2-3]$ & 0.70 \\
\hline Worst pain in the last 8 days & $1[0-3]$ & $1[0-2]$ & 0.44 \\
\hline Pain during the last 8 days & $0[0-1]$ & $0[0-2]$ & 0.98 \\
\hline Effect of pain on mood & $0[0-2.5]$ & $0[0-2]$ & 0.72 \\
\hline Effect of pain on walking & $0[0-2.5]$ & $0[0-3]$ & 0.69 \\
\hline Effect of pain on child care tasks & $0[0-2]$ & $0[0-2]$ & 0.72 \\
\hline Effect of pain on usual chores & $0[0-2.5]$ & $0[0-2]$ & 0.72 \\
\hline
\end{tabular}

v: Van Elteren, IQR: interquartile range

associated anterior lacerations, and breech and twin pregnancies that induced maneuvers that could cause additional pain. We also excluded cases which used continuous sutures with one thread and one knot for all the plans, which reduces postpartum pain [26].

Perineal infiltration with levopubivacaine was not more effective than placebo in decreasing episiotomy or laceration pain after delivery. This result is consistent with the results of the prospective randomized study by Schinkel et al. [18], which study compared pain after infiltration of $15 \mathrm{~mL}$ of ropivacaine $0.75 \%$, another long-acting anesthetic, lidocaine $1 \%$, and a placebo for pain after episiotomy in women without operative vaginal deliveries. It showed no difference during the first 24 hours postpartum. These findings are not consistent from previous literature in other fields. Analgesic infiltrations have proved their effectiveness in reducing postoperative pain in surgery of the anal wall and perineum in treating hemorrhoids [27,28]. They act on the very numerous intraepithelial nociceptive receptors of the anal canal and the deep branches of the pudendal nerve. They are part of multimodal pain management and thus promote early rehabilitation [29].

The pain associated with episiotomy or perineal tears or lacerations thus appears to be a good candidate for infiltration of local longacting anesthetics. Preliminary studies showed its potential interest for episiotomy. In a before-and-after study of a small number of women with and without operative vaginal deliveries, Sillou et al. [20] showed that an infiltration of $10 \mathrm{~mL}$ ropivacaine $0.75 \%$ effectively reduced pain in the first 24 hours postpartum. But this study was neither randomized nor blinded and combined deliveries with and without operative vaginal deliveries. Gutton et al. [19] also conducted a beforeand-after study of 102 women to compare $20 \mathrm{~mL}$ of lidocaine and 20 $\mathrm{mL}$ of ropivacaine $0.75 \%$ after episiotomy in a population with and without operative vaginal deliveries. They found a significant difference in favor of ropivacaine for the pain scores during the first 48 hours. In a randomized, prospective single-blinded study of 92 women, Bolandard et al. [21] also assessed the utility of perineal infiltration with $20 \mathrm{~mL}$ of lidocaine $1 \%$, or ropivacaine $0.2 \%$ and $0.75 \%$ for postpartum perineal pain management. Although perineal infiltration with ropivacaine in the two doses before perineorrhaphy did result in an absence of postpartum pain in $25 \%$ of the cases on average versus $6 \%$ in the lidocaine group and also delayed the first intake of analgesics by 10 hours, this study failed to show a significant difference in terms of pain in the different groups. Unfortunately, we had little information about this series, published only as a conference abstract. Beyond the poorer quality of the studies favoring ropivacaine, other factors may explain the non-superiority of the long-acting local anesthetic in our study. The $10-\mathrm{mL}$ quantity of levobupivacaine might have been inadequate, especially because of the strong reabsorption in this area, which explains the lesser effectiveness of wound infiltration compared with plexus blocks (for the obturator nerve). Moreover, perineal pain after delivery is not localized to the area of the episiotomy but affects the entire genital area; accordingly, reducing the wound/incision pain may also be inadequate. Finally, the lack of a difference in pain between rest and motion is further support for the conclusion that levobupivacaine is ineffective in this situation. Finally, still another factor might influence these results. The studies reporting positive effects of longacting local anesthetics included operative vaginal deliveries and had higher mean NRS scores than the studies not including such deliveries [18-21]. A low overall level of pain decreases the likelihood of detecting differences between treatment groups. Excluding patients who required an instrumental delivery, such as forceps or spatulas, may have selected patients likely to experience low levels of perineal pain after delivery. Such deliveries cause more maternal trauma and therefore more pain than spontaneous vaginal and vacuum deliveries [30]. Standard analgesia with an NSAID and oral paracetamol is not effective in 33\% of women with post-episiotomy pain [31] and in $78 \%$ of women with forceps delivery [32]. Accordingly, although infiltration of long-acting local anesthetics did not appear very beneficial in a population with spontaneous or vacuum-assisted vaginal deliveries, it might merit study specifically for the populations with operative deliveries by forceps or spatulas, where it might be more useful. 


\section{Conflict of interest}

None.

\section{References}

1. East CE, Sherburn M, Nagle C, Said J, Forster D (2012) Perineal pain following childbirth: prevalence, effects on post natal recovery and analgesia usage. Midwifery 28: 93-97. [Crossref]

2. Sleep J, Grant A (1987) West Berkshire perineal management trial: three year follow up. Br Med J (Clin Res Ed) 295: 749-751. [Crossref]

3. Albers L, Garcia J, Renfrew M, McCandlish R, Elbourne D (1999) Distribution of genital tract trauma in childbirth and related postnatal pain. Birth 26: 11-17. [Crossref]

4. Macarthur AJ, Macarthur C (2004) Incidence, severity, and determinants of perineal pain after vaginal delivery: a prospective cohort study. Am J Obstet Gynecol 191: 11991204. [Crossref]

5. Hartmann K, Viswanathan M, Palmieri R, Gartlehner G, Thorp J Jr, et al. (2005) Outcomes of routine episiotomy: a systematic review. JAMA 293: 2141-2148. [Crossref]

6. Carroli G, Mignini L (2009) Episiotomy for vaginal birth. Cochrane Database Syst Rev 9: CD000081.

7. Blondel B, Lelong N, Kermarrec M, Goffinet F, Coordination nationale des Enquêtes Nationales Périnatales (2012) Trends in perinatal health in France between 1995 and 2010: Results from the National Perinatal Surveys. J Gynecol Obstet Biol Reprod (Paris) 41: 151-166. [Crossref]

8. Sanders J, Peters TJ, Campbell R (2005) Techniques to reduce perineal pain during spontaneous vaginal delivery and perineal suturing: a UK survey of midwifery practice. Midwifery 21: 154-160. [Crossref]

9. Rajan L (1994) The impact of obstetric procedures and analgesia/anaesthesia during labour and delivery on breast feeding. Midwifery 10: 87-103. [Crossref]

10. Buhling KJ, Schmidt S, Robinson JN, Klapp C, Siebert G, et al. (2006) Rate of dyspareunia after delivery in primiparae according to mode of delivery. Eur J Obstet Gynecol Reprod Biol 124: 42-46. [Crossref]

11. Behotas S, Chauvin A, Castiel J, Martin A, Boureau F, et al. (1992) [Analgesic effect of ibuprofen in pain after episiotomy]. Ann Fr Anesth Reanim 11: 22-26. [Crossref]

12. Wuytack F, Smith V, Cleary BJ (2016) Oral non-steroidal anti-inflammatory drugs (single dose) for perineal pain in the early postpartum period. Cochrane Database Syst Rev 7: CD011352. [Crossref]

13. Niklasson B, Börjesson A, Carmnes UB, Segerdahl M, Ohman SG, et al. (2012) Intraoperative injection of bupivacaine-adrenaline close to the fascia reduces morphine requirements after cesarean section: a randomized controlled trial. Acta Obstet Gynecol Scand 91: 1433-1439. [Crossref]

14. Aasbo V, Thuen Sherburn M, Nagle C, Said J, Forster DÒA, et al. (2002) Improved long-lasting postoperative analgesia, recovery function and patient satisfaction after inguinal hernia repair with inguinal field block compared with general anesthesia. Acta Anaesth Scand 46: 674-678. [Crossref]

15. Apostolopoulos K, Labropoulou E, Samaan R, Bogris K (2003) Ropivacaine compared to lidocaine for tonsillectomy under local anaesthesia. Eur Arch Otorhinolaryngol 260: 355-357. [Crossref]
16. Jebeles JA, Reilly JS, Gutierrez JF, Bradley EL Jr, Kissin I (1991) The effect of preincisional infiltration of tonsils with bupivacaine on the pain following tonsillectomy under general anesthesia. Pain 47: 305-308. [Crossref]

17. Brunat G, Pouzeratte Y, Mann C, Didelot JM, Rochon JC, et al. (2003) Posterior perineal block with ropivacaine $0.75 \%$ for pain control during and after hemorrhoidectomy. Reg Anesth Pain Med 28: 228-232. [Crossref]

18. Schinkel N, Colbus L, Soltner C, Parot-Schinkel E, Naar L, et al. (2010) Perineal infiltration with lidocaine $1 \%$, ropivacaine $0.75 \%$, or placebo for episiotomy repair in parturients who received epidural labor analgesia: a double-blind randomized study. Int J Obstet Anesth 19: 293-297. [Crossref]

19. Gutton C, Bellefleur JP, Puppo S, Brunet J, Antonini F, et al. (2013) Lidocaine versus ropivacaine for perineal infiltration post-episiotomy. Int J Gynaecol Obstet 122: 33-36. [Crossref]

20. Sillou S, Carbonnel M, N'Doko S, Dhonneur G, Uzan M, et al. (2009) [Postpartum perineal pain: effectiveness of local ropivacaine infiltration]. J Gynecol Obstet Biol Reprod (Paris) 38: 510-515. [Crossref]

21. Bolandard F, Hupin A, Bonnin M, Mission JP, Duband P, et al. (2004) Comparaison de l'infiltration périnéale par lidocaïne $1 \%$, ropivacaïne $2 \mathrm{mg} / \mathrm{ml} \mathrm{et} 7,5 \mathrm{mg} / \mathrm{ml}$ pour l'analgésie périnéale en suites de couches (résumé). Ann Fr Anesth Reanim 23: 243 [R109].

22. Zink W, Graf BM (2008) The toxicity of local anesthetics: the place of ropivacaine and levobupivacaine. Curr Opin Anaesthesiol 21: 645-650. [Crossref]

23. Kakagia D, Fotiadis S, Tripsiannis G (2005) Levobupivacaine versus ropivacaine infiltration analgesia for mastopexy: a comparative study of 2 long-acting anesthetic drugs in infiltrative anesthesia for mastopexy. Ann Plast Surg 55: 258-261. [Crossref]

24. Zeren S, Kesici S, Kesici U, Isbilir S, Turkmen UA, et al. (2013) Effects of levobupivacaine on wound healing. Anesth Analg 116: 495-499. [Crossref]

25. Leone S, Di Cianni S, Casati A, Fanelli G (2008) Pharmacology, toxicology, and clinical use of new long acting local anesthetics, ropivacaine and levobupivacaine. Acta Biomed 79: 92-105. [Crossref]

26. Kettle C, Hills RK, Ismail KM (2007) Continuous versus interrupted sutures for repair of episiotomy or second degree tears. Cochrane Database Syst Rev: CD000947. [Crossref]

27. Nordin P, Zetterström H, Gunnarsson U, Nilsson E (2003) Local, regional, or general anaesthesia in groin hernia repair: multicentre randomised trial. Lancet 362: 853-858. [Crossref]

28. Vinson-Bonnet B, Coltat JC, Fingerhut A, Bonnet F (2002) Local infiltration with ropivacaine improves immediate postoperative pain control after hemorrhoidal surgery. Dis Colon Rectum 45: 104-108. [Crossref]

29. Kehlet H (1997) Multimodal approach to control postoperative pathophysiology and rehabilitation. Br J Anaesth 78: 606-617. [Crossref]

30. Johanson RB, Menon BK Vacuum extraction versus forceps for assisted vagina delivery. Cochrane Database Syst Rev: CD000224.

31. Khan GQ, Lilford RJ (1987) Wound pain may be reduced by prior infiltration of the episiotomy site after delivery under epidural analgesia. Br J Obstet Gynaecol 94: 341344. [Crossref]

32. Peter EA, Janssen PA, Grange CS, Douglas MJ (2001) Ibuprofen versus acetaminophen with codeine for the relief of perineal pain after childbirth: a randomized controlled trial. CMAJ 165: 1203-1209.

Copyright: (C2017 Carbonnel M. This is an open-access article distributed under the terms of the Creative Commons Attribution License, which permits unrestricted use, distribution, and reproduction in any medium, provided the original author and source are credited. 